\title{
The main dynamics of sunflower research presented at the 19th International Sunflower Conference in 2016
}

\author{
Etienne Pilorgé ${ }^{1, *}$, Sylvie Dauguet ${ }^{2}$, Christophe Jestin $^{1}$ and Emmanuelle Mestries ${ }^{3}$ \\ 1 Terres Inovia, Av Lucien Brétignières, 78850 Thiverval-Grignon, France \\ 2 Terres Inovia, Parc industriel, 11 rue Gaspard-Monge, 33600 Pessac, France \\ 3 Terres Inovia, Centre de recherche INRA de Toulouse, Bâtiment AGIR, 24 chemin de Borde Rouge, CS 52627, 31326 Castanet- \\ Tolosan, France
}

Received 18 December 2019 - Accepted 9 March 2020

\begin{abstract}
The International Sunflower Conference takes place every four years under the auspices of the ISA, International Sunflower Association. Before the 20th Conference in June 2020, a review of the proceedings of the Edirne conference, in June 2016, offers a vision of the crop and research dynamics in the world, as well as international cooperation programmes in progress or to be developed in the period 20162020. They are essential for the future of this crop for which demands tend to diversify. Sustained efforts have led to significant progress in genomics. The challenges posed by pests and by climatic constraints remain significant. The interest in gathering knowledge on crop models incorporating varietal parameters appears clearly, both to establish long-term adaptation strategies and to make better use of current resources.
\end{abstract}

Key words: sunflower / research dynamics / genetics / pests management / climate change

Résumé - Les principales dynamiques de la recherche sur le tournesol vues à partir de la $19^{\mathrm{e}}$ Conférence internationale sur le tournesol. La Conférence internationale du tournesol a lieu tous les quatre ans sous l'égide de l'International Sunflower Association (ISA). Avant la $20^{\mathrm{e}}$ Conférence en juin 2020, une revue des contenus de la conférence d'Edirne, tenue en juin 2016, offre une vision des dynamiques de recherche et de la culture dans le monde, ainsi que des programmes de coopération internationale en cours ou à développer sur la période 2016-2020. Ils sont essentiels pour l'avenir de cette culture pour laquelle la demande a tendance à se diversifier. Les efforts soutenus ont amené des progrès déterminants en génomique. Les défis posés par les bioagresseurs et les contraintes climatiques restent prégnants. L'intérêt de rassembler les connaissances dans des modèles de culture intégrant des paramètres variétaux apparaît tant pour établir des stratégies d'adaptation à long terme que pour mieux utiliser les ressources actuelles.

Mots clés : tournesol / dynamiques de recherche / génétique / protection des cultures / changement climatique

\section{Introduction}

The International Sunflower Conferences, held every four years under the auspices of the International Sunflower Association (ISA), are meetings that provide an inventory of research for the development of the sunflower crop. The 19th Conference was held in Edirne, Turkey, from May 30 to June 1, 2016, organized by ISA and the University of Thrace, in a delicate political and security context. Nevertheless, it was attended by more than 500 delegates including about 350 foreign participants from 26 countries. In preparation for the next Conference, at Novi-Sad (Serbia) in June 2020, this

\footnotetext{
* Correspondence: e.pilorge@terresinovia.fr
}

paper provides a review of presentations at Edirne and research aims suggested for 2016-2020.

At Edirne, there were nine plenary lectures and four specialized sessions: "Genetics and breeding", "Molecular genetics", "Biotic and abiotic stress tolerance", "Crop production and management". A large part of the papers dealt with genetics, breeding, and resistance to stress and relatively few on crosscutting or interdisciplinary subjects, most often dealt with in the session "Crop production and management". A specific symposium on the quality of the oil was also held (Fig. 1).

\section{Key collaborations in genomics}

The first sequencing of the sunflower genome (Stéphane Muños, France, plenary conference), using the PacBio 


\section{Number and proportion of communications in main research areas}

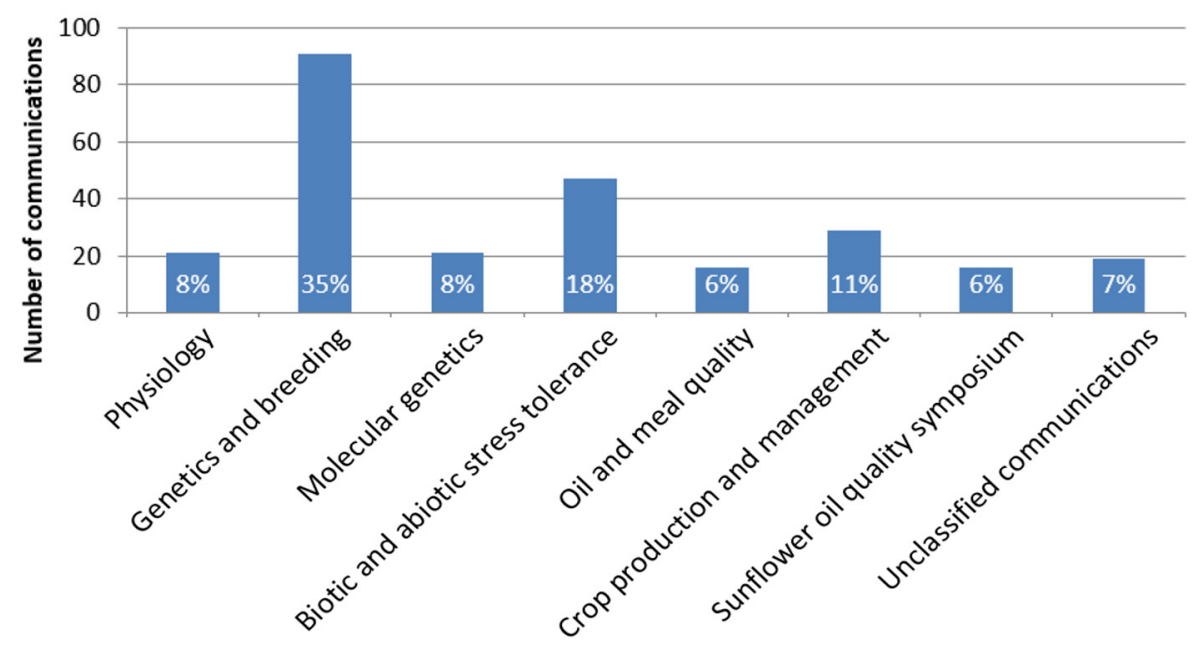

Fig. 1. Number and proportion of communications in main research areas.

technology acquired in 2015 by INRA in Toulouse with the support of French professional organizations, was the most important step forward. The inbred line XRQ, which is also used in the Sunrise project, was sequenced and showed, after assembly, a genome size of $3.03 \mathrm{~Gb}$ ( $80 \%$ of the genome). The integration of the different high-density maps made it possible to construct pseudomolecules (chromosomes), with $98.5 \%$ contigs and $98 \%$ mapped transcripts. The Busco index (set of genes conserved in plants) is $92 \%$ in sunflower according to this sequencing, similar to that of tomato. The perspectives announced focused on improvement of assembly by optical mapping and the sequencing of other lines in addition to XRQ and HA412, which do not reflect all the existing genetic variations.

The understanding of genes also progressed through "pan genome" analysis (Hubner et al., Canada) conducted jointly by Canadian, American and French teams in order to search for genes of interest coming from wild ecotypes and integrated in cultivated sunflower during the process of domestication. Of a total of 19000 genes identified from genome sequencing of 288 core-collection accessions, approximately 3350 are unique and among them some are involved in stress resistance. A meeting of the "International consortium for sunflower genomic resources" was held to review the period 20122015, and to specify the objectives for 2016-2019. This consortium brought together public sector organizations (INRAE, University of Georgia and University of British Columbia) and private sector organizations (Advanta, Biogemma, Bayer, KWS, Syngenta, Dupont, Corteva ex-Pioneer). It has the aim of assembling and annotating the reference sequence of the sunflower genome, integrating reference sequences with physical and genetic maps, developing a collection of Expressed Sequence Tags (EST), obtaining association genetics data and analyzing the genome of wild species. The consortium already produced two reference sequences, for XRQ (PacBio) and HA412 (454 Illumina), a reference sequence of the mitochondrial genome and a transcriptome atlas. In order to progress in the annotation of the sunflower genome and develop bioinformatic tools, an Association Mapping (AM) population of 288 genotypes was resequenced and phenotyped for key traits in agriculture. In addition, 400 pre-breeding lines from 26 wild donors were produced and genotyped.

The consortium, ready to welcome new partners, planned for the 2016-2019 period to focus on four actions: production of the genomic sequence of key sunflower genotypes (16 inbred lines + wild sunflower genotypes), development and characterization of genetic resources including a tilling population created by INRAE, development of new genotyping tools (SNPs and structural variants) and creation of an atlas of stress response genes (through transcriptomic analysis).

\subsection{Wild genetic resources: a key investment for the future, under US leadership}

In terms of genetic resources, which are fundamental for broadening the genetic base of domestic sunflower, work continued on the identification and management of these resources, and on their characterization. Among the wild species, $H$. anomalus is the species with the highest seed weight: $6 \mathrm{~g}$ per 1000 seeds and the highest oil content (40\%). Collecting wild species is long and difficult: Seiler et al. (USA) traveled $3700 \mathrm{~km}$ in the deserts of Utah and Arizona to collect 10 populations of $H$. anomalus and five populations of $H$. deserticola harvesting $2-$ 3000 seeds per population, which enriched the USDA-ARSNPGS gene bank. The US National Plant Germplasm System (NPGS) was introduced by Laura Marek in her plenary lecture. It has 20 sites under the leadership of the USDA-ARS. The collection includes about 2500 accessions of domestic sunflower and 2500 of wild species, including 2200 with seed availability for each type. The superposition of climatic zones and geographical origins of the accessions present in the collection led to the identification of gaps and a phase for collecting samples was launched in 2015 in two regions: Utah and Arizona and Florida and Alabama: 188 new accessions were collected, representing 17 species. In addition to these American accessions, the NPGS manages samples from 30 different countries.

Other collections exist in Argentina (Cordoba), Turkey (Izmir), Russia (Saint Petersburg), Canada (Saskatoon), Serbia 
(Novi-Sad) and France (Toulouse). All NPGS accessions are available (website), with a standard MTA in general. Between 2011-2015, out of 755 orders, $20 \%$ came from outside the USA. Beyond collection and conservation, the characterization of these resources was crucial, representing a very important effort (disease resistance, oil quality and, in future, insect resistance). In India, the Indian Council of Oilseeds Research worked on this (Sujatha et al., India). Their conservation is spread over 11 regions of the country and their characterization focused on resistance to diseases (powdery mildew, Alternaria, downy mildew), yield and oil content, height and phenology. A new source of cytoplasmic male sterility was developed (ARG-6) from Helianthus argophyllus. Canadian research, in collaboration with Soltis and the Uganda National Agriculture Research Organization (NARO), evaluated pre-breeding hybrids from crosses between 22 wild Helianthus species and the inbred line HA89 (Baute et al., Canada). This evaluation focused on drought resistance with three field experiments in Uganda and on oil content with one experiment in France. The material is distributed via the USDA. In France, a Center for Biological Resources (CRB) dedicated to sunflowers was set up at INRA, Toulouse, in 2012. Its vocation is the conservation, multiplication and distribution of genetic resources. Its collection includes the material collected and created at INRA since the early 1960s. The CRB is also involved in the creation, maintenance and dissemination of genetic material dedicated to scientific studies such as genetic mapping populations, interspecific lines, EMS mutants, representing today nearly 3000 entries. The CRB provides molecular characterization of this material (SNP genotyping) to improve management and assess diversity.

\section{Methodological advances in genetics for an increasingly segmented selection}

In the plenary conference "Contemporary challenges in sunflower breeding", Branislav Dozet gave his vision of the orientations for the research regarding the selection and the inventory of the recent technological evolutions and their limits. He noted significant progress in genomic techniques, but very little in "precise phenotyping". This gap made it important to encourage development of new tools (digital phenotyping, hyperspectral drones, sensor platforms, etc.) because their lack hampered the identification of QTLs. There have been metabolomic studies including metabolite profiles related to phenotypic expression, used to study of resistance to Orobanche cumana (wall thickening, lignin synthesis).

The development of haploidization technologies was not yet successful in sunflower compared with other crop species. Techniques of mutagenesis (tilling) made it possible to publish many mutations, but few of them led to commercial applications. Genomic selection was being developed. Crop models have been developed to take into account IGEC (Genotype $\times$ Environment $\times$ cropping practices interactions). B. Dozet concluded by noting that sunflower in 2016 was an increasingly segmented crop (with about 24 major market segments, compared to a dozen in 2000), which required more resources, and that an important point remained the gap between genetic progress observed in trials and in farmers' fields, wider than for soybean and maize.
The French project SUNRISE (SUNflower Resources to Improve Yield Stability in a Changing Environment; http:// www.sunrise-project.fr/en/) specifically invested in the bottleneck concerning phenotyping (Langlade et al., France). It combined several approaches, including implementation of high-throughput phenotyping strategies to characterize molecular, physiological and agronomic responses of sunflowers to the variation of the abiotic environment, in particular with regard to water constraints. QTL involved in the response of sunflower to abiotic stress (drought, nitrogen stress and asphyxia) were identified. Applied to the French corecollection, this approach made it possible to calculate a "multi-stress" index and to identify five to 20 QTL under stress. For example, for cold resistance, nine SNPs explaining 10 to $20 \%$ of the yield variability were identified on different chromosomes. The genes involved concern protein transport, membrane protection and root development. The perspectives for this work were to apply the approach to biotic stresses (e.g. downy mildew and broomrape), to develop biomarkers for these biotic and abiotic stresses, to improve phenotyping and to understand the functional mechanisms of stress response to improve the predictive quality of association genetics and genomic selection models in order to design ideotypes adapted to climate change.

A study on apical branching had been motivated by the possible interest of this phenotype for drought resistance (Duriez et al., France): the desynchronization of flowering would make all flower heads not subjected to the same stress. The branching-controlling gene b1 was mapped to the LG10 in a $0.3 \mathrm{~cm}$ window. This locus was positively selected in branched male sunflowers but no selection pattern was identified in wild sunflowers. The role of this gene in cellular processes needed further exploration.

Horn (Germany) presented work on the biosynthetic and signaling pathways of gibberellin (GA) involved in plant growth: from known sequences in other species, counterparts were sought in sunflower: 18 genes were highlighted. Functional analysis confirmed the equivalent of these genes in A. thaliana. The study also highlighted a sub-functionalization of genes. Molecular screening had been engaged in a collection. Horn also highlighted the use in breeding of PET2, a CMS system (cytoplasmic male sterility) different from PET1. Like the latter, CMS PET2 is from an interspecific cross H. petiolaris $*$ H. annuus. However, the rearrangements observed in the PET2 cytoplasm are different from those of PET1. Markers associated with the fertility restoration gene Rf_PET2 were developed and mapped to LG13.

\section{Studies on abiotic stresses and physiology at the crossroads of genetics and agronomy}

Water stress remained a major concern in both breeding and agricultural practices. Proteomic analysis (Ghaffari et al., Iran) performed on contrasting genotypes for drought showed that in susceptible and tolerant lines, respectively 21 of the 347 and 27 of the 363 proteins were significantly affected by stress. Afifuddin Adiredjo (Indonesia/France) presented the interest of isotopic carbon discrimination for the study of genetic control of water use efficiency, making it possible to 


\section{Evolution of communications on biotic stresses to ISA \\ Conference $2016 / 2012$ \\ in \% (Mar del Plata 2012: 51 communications / Edirne 2016: 76 communications)}

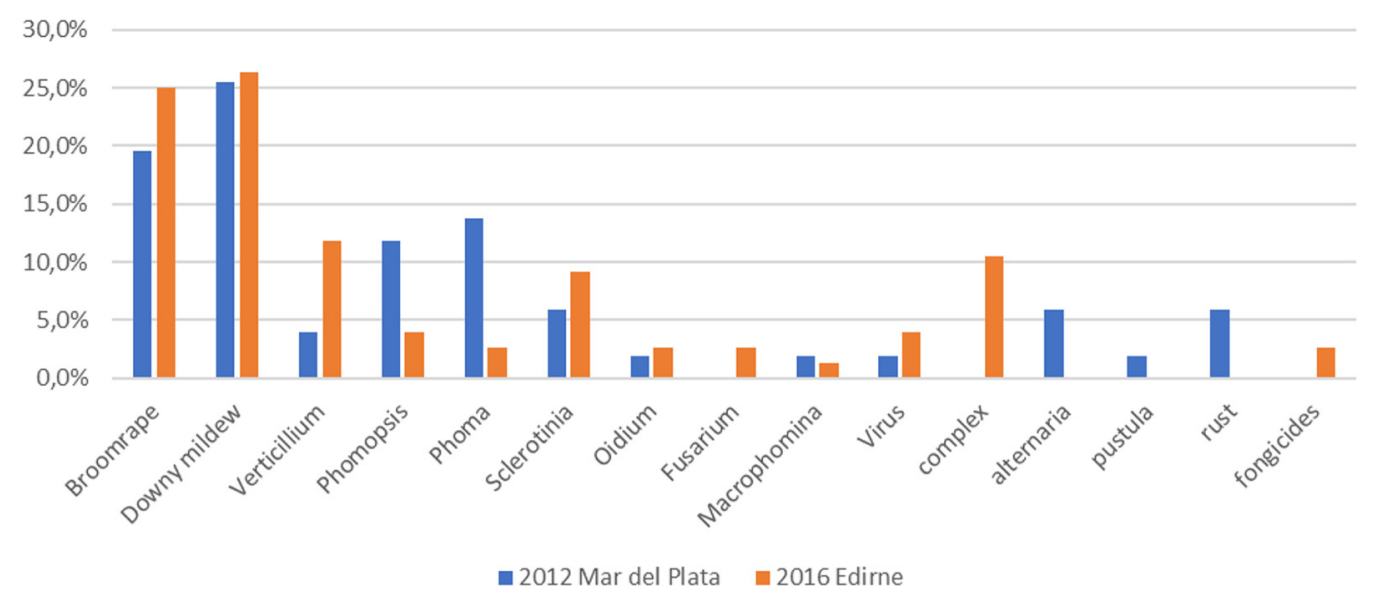

Fig. 2. Evolution of communications on biotic stresses to ISA Conference 2016/2012.

discriminate genotypes with high water use efficiency (WUE), high biomass, and combining these two characteristics at the same time. Hussain et al. (Pakistan) used an in vitro culture technique on medium enriched with $10 \%$ polyethylene glycol (PEG 600) to test populations of H. annuus and H. argophyllus as well as intra- and interspecific hybrids of these species, leading to selection of 43 out of 160 genotypes for which characters of interest for water stress tolerance were distinct: root length, young stem length, vigor, etc. Thanks to a lethal dehydration threshold leaf test (RWC variation - relative water content - under water stress), differences in tolerance to senescence were found between varieties, some maintaining an active and green leaf surface after stress (Arslan et al., Turkey). Shanwad et al. (India) showed that the application of a hydrogel on the soil, the treatment of seeds with $\mathrm{CaCl} 2$ and the addition of amendments such as vermicompost and gypsum, made it possible to increase yields in a dry cropping situation, in a semi-arid tropical environment. Tolerance to cold was the subject of work in Morocco in 2013 and 2014 (Houmanat et al.) to anticipate sowing dates to advance the cropping cycle: of 46 genotypes sown in early January, 14 showed tolerance to cold temperatures (minimum January-February $-5^{\circ} \mathrm{C}$ ).

A study by Blackman and Harmer (USA) focused on the sunflower heliotropism mechanism. The mechanism was described and modeled from digital images taken during the circadian cycle. The phenomenon faded in continuous light (photoperiod 24h) and also as the crop cycle advanced and after flowering. The authors showed a quite strong genetic variability on the speed of return to the "East" position during the night. One point was remarkable: the differential in speed to return to maximum exposure in the morning for the flower head generated differences in the rate of warming of the florets. The authors suggested that this differential could explain the variability of attractiveness for bees: the more rapidly a capitulum returns to maximum exposure in the morning, the warmer it becomes, making florets more attractive for bees. This hypothesis needs further exploration.

Two Turkish presentations (H. Samet, Y. Cikili) on soil cadmium toxicity stress reported greenhouse experiments with nutrient solutions at different levels of cadmium concentration ( 0 to $1 \mathrm{mM}$ ), the plants being harvested after 20 days. Shoot growth was affected from $0.1 \mathrm{mM}$, but roots were affected only with $1 \mathrm{mM}$ cadmium. As observed in French studies, the concentration of cadmium in sunflower roots is higher than in the shoot. The addition of cadmium to the soil solution had a negative effect on zinc absorption from $0.1 \mathrm{mM}$, as well as on chlorophyll content. The second presentation focused on the relationship between cadmium and potassium in sunflower. It showed that application of $\mathrm{K}$ reduced the $\mathrm{Cd}$ content in the shoot and roots and reduced its translocation from roots to stems and leaves.

\section{Biotic stresses: the difficult subject of the evolution of downy mildew and broomrape races and increase in Verticillium infections}

A total of 20 papers and 38 posters were proposed on diseases and broomrape, in addition to two plenary presentations by Lili Qi (USA) and Stefan Masirevic (Serbia).

Downy mildew and broomrape remain the two pathogens that are the subject of the greatest number of studies, followed by Verticillium, mainly in France, and Sclerotinia. On the contrary, there were few presentations on Phomopsis and Phoma (Fig. 2).

Several abstracts and papers offered a review of the presence and evolution of pathogens: history and evolution of downy mildew races (Bazzalo et al., Argentina, Gilley et al., United States), evolution of the parasite complex (Encheva, Bulgaria), inventory of diseases present in northern Greece (Anastasiades, Greece) with prevalence of phoma, macrophomina and septoria in this country, and presence of powdery mildew in India (Sujatha). Only a few papers concerned integrative modeling: Nuñez-Bordos et al. (Argentina) described the construction of a relationship between the source/sink ratio and phoma on stem, and Aubertot (France) reported on the IPSIM platform, which aimed to predict the damage patterns on sunflower from cultural practices, soil, 
weather conditions and field environment, based on a review of the literature and expert knowledge. Jinga et al. (Romania) evaluated a set of 24 commercial hybrids against multiple parasites: on one field site in 2014 (year with high rainfall favorable to diseases), the percentage of plants affected by phomopsis, sclerotinia, Alternaria and broomrape was noted and a recommended list was developed. However, few details were provided on observation dates and interactions between these bio-aggressors.

\subsection{Downy mildew}

Lili Qi (USA) observed, in a plenary conference, that the two races of downy mildew identified in the 1980s had increased to about 40 in 2016, and drew up the state of play in terms of mapping of new genes for specific resistance (Pl17 on LG4, Pl18 on LG2), of development of SNP markers associated with Pl8 and PlArg and on the marker-assisted pyramiding of these two genes. Pll7 and Pll8 provided resistance to all races identified in the United States. Several $P l$ genes originated from H. argophyllus: PlArg (LG1), Pl8 (LG13), Pl18. Pl17 came from a wild H. annuus, highlighting the importance of sources of wild resistance. In his plenary lecture on the progress of sunflower disease research and control, Stefan Masirevic (Serbia) noted that the downy mildew remained the disease mobilizing most efforts; with more than 40 races known, including 21 in the United States, 18 in Canada and five in Argentina, the situation would remain "stable", but it was not clear which countries were monitoring this pathogen. In Czech Republic, seven new races had been detected: 705 and 715 . The need to enlarge the set of differential hosts for the precise identification of races was underlined by several speakers and a meeting was held on the sidelines of the conference. A molecular study of sunflower response to downy mildew was presented by Sestacova (Moldova) on 22 genes involved in systemic acquired resistance (SAR) and reactive oxygen species (ROS) metabolism. She showed the involvement of different genes including PR5, PAL, defensin, but also transcription factors (TGA1,5, WHY1). For the control of downy mildew, the performances of new seed treatments were also mentioned (oxathiapiproline [OXTP], Brandl, Syngenta) whose evaluation was yet to come in Europe (2019-2021).

\subsection{Verticillium}

Presentations were mainly French and Chinese. In China, Zhang et al. (Inner Mongolia University) studied seed transmission and showed fungus progression in tissues, followed by microscopy (after transformation with GFP fluorescent proteins of a Verticillium strain). PCR analysis detected the fungus in the hull and seed coat on 10 to $25 \%$ of the seeds of nine varieties (analysis made on 16 to 40 seeds per genotype). However, no microsclerotia were detected in seeds and the health status of the seedlings from these infected seeds had not yet been checked. In France, the first results acquired in the framework of the CRUCIAL project on the potential of biofumigation to combat Verticillium were presented by Seassau (France, INP Purpan). Several seed companies were interested in this pathogen. Syngenta supported a thesis
(Missonnier, France) on the diversity of the fungus, spatial analysis of variability of disease severity within plots and on relations between fungal diversity and breeding strategies. Analysis of strains from susceptible and resistant genotypes with varying infestation levels showed that all genotypes with symptoms were colonized by Verticillium dahliae, and $75 \%$ of the symptomless genotypes were colonized by an unidentified Verticillium species. There was no correlation between the pathogen quantity and infestation level. Further genomic studies appeared necessary to study the diversity of Verticillium and determine the profiles able to colonize sunflower. Verticillium was also a concern for the seed company Limagrain: two reports described evaluation of varieties in Argentina: the INTA Balcarce seedling protocol was used to evaluate 18 Argentine hybrids at the seedling stage, in a greenhouse, against two isolates representative of the Argentine "variants" (Crova et al., Argentina). The hybrids were also evaluated in the field (Capurro and Rita, Argentina), in sunflower monoculture on a very infested plot: comparison of Argentinean and European hybrids shows significant differences between them, with a range of variability within both types of material. Fernandez et al. (Spain) associating the CSIC and Corteva (ex-Pioneer), showed variations in the virulence and aggressiveness of the fungus among an international collection of seven isolates, and an "isolate $\times$ genotype" interaction eight weeks after artificial contamination. They also mentioned that the new "race" of $V$.dahliae recently identified in Spain had also been identified in Romania and France. Variation in this pathogen remains poorly apprehended.

\subsection{Sclerotinia}

Qi (USA) reported the identification of six QTLs in a RIL population, involved in resistance to stem basis attacks in five environments over three years (accounting for between 6 and $32 \%$ of phenotypic variability), and with highly significant genotype $\times$ environment interactions. One QTL was detected in all environments. The few reports on resistance to this pathogen showed little progress. One example of biological control was presented on the potential of Trichoderma spp. on seedlings in the laboratory (Tančič Živanov, Serbia).

Phomopsis: There were few communications, but this disease was very present in three provinces of Argentina, whereas it was reported before 2016 only sporadically (CorroMolas et al.) and was identified as Phomopsis helianthi by Thompson in Australia. The presentation by S. Thompson concerned the Australian situation with the continued practice of minimum or non-tillage for 25 years, favoring the constitution of inoculum reservoirs. The first major attack of phomopsis in Australia took place in 1999. Thompson reported three new species of Diaporthe in Australia (D. gulyae, D. kongii, D. kockmanii) and observed that use of molecular techniques revealed errors in earlier identifications, 12 to 15 new species being likely, Diaporthe showing wide, largely unexplored, diversity. The presentation also concerned the role of weeds (including some thistles, Asteraceae) and some crops (soybean, chickpea, and even maize) as living reservoirs of the disease (green bridges), as well as the role of crop residues or residues of weeds killed by 
herbicides (brown bridges). The absence of soybean the year prior to sunflower cultivation could reduce Diaporthe infestation by $42 \%$.

\subsection{Phoma}

Stevan Masirevic (Serbia) reported that the perfect form was identified in new areas. Molecular advances in systematics led to propose a new name: Plenodomus lindquistii.

\subsection{Powdery mildew}

According to Sujatha (India), the main sunflower diseases in India were Alternaria, downy mildew, powdery mildew, rust, sclerotinia and macrophomina. Powdery mildew had become a major problem since 2008, observed even on seedlings, with yield losses estimated between 13 and 20\%. Several sources of resistance had been identified, especially in wild Helianthus. The variability of the pathogen, Golovinomyces cichoracearum, was studied across the territory (10 regions) and a method of contamination with conidial suspensions developed. This allowed evaluation of a range of wild Helianthus with different resistance levels, to observe colonization of the tissues and to initiate studies on genetic control of quantitative resistance and identification of the genes through the analysis of transcripts.

Genetic tolerance to Alternaria was also a focus of attention in India (Meena et al., India). Tolerance characters were identified in two wild sunflower species (H. mollis and H. maximiliani), offering interesting prospects for breeding. Alternaria develops in warm and wet climates (for example, the rainy season in Africa) and can lead to complete defoliation. Qi (USA) provided an update for rust (Puccinia helianthii) with 38 races identified in the USA, mapping of seven specific resistance genes to this disease and the creation (and diffusion) of two lines pyramiding two sources of resistance.

\subsection{Broomrape}

Following the overview provided by Maria Joita-Pacureanu (Romania), in a plenary lecture, the communications focused on distribution and knowledge of the O. cumana races, analysis of their genetic diversity and deciphering of hostparasite interaction processes. The sequencing of O. cumana, based on the PacBio technique, using a homozygous $\mathrm{F}$ race, (Munos, France), carried out jointly by INRA and CSIC (Spain) teams was an important step forward. Genome size was estimated at $2 \mathrm{~Gb}$ by flow cytometry. Assembly after sequencing made it possible to obtain $1.5 \mathrm{~Gb}, 75 \%$ of the genome. Annotation of the genome was still in progress in 2016. Genetic diversity of Orobanche (Coque et al., France) was studied based on the collection and analysis of over 800 seed samples from 74 sites in seven countries. Phenotyping was performed using a set of four differential hosts on Biogemma's Oroscreen ${ }^{\infty}$ platform and classified the samples into three large groups: E, F and G. Almost all the collection was also characterized using a set of about 1500 SNPs. This made it possible to identify by ACP:
- France-Spain and Eastern Europe pools, with East-West structuring;

- differentiation between samples from Eastern Europe;

- differentiation of two pools in Spain.

This structure was not associated with virulence, but there was a correlation between virulence and level of heterozygosity. A set of 200 SNPs produced by the project, was distributed by Biogemma for diversity studies. Work on the genetic characterization of the interaction made it possible to highlight the phenomenon of incompatible attachment, which is an important resistance process (Louarn et al., France). It results from a modification of sunflower root cells, forming a barrier that prevents the parasite from connecting to the host vascular system. Several genes regulated at the beginning of the interaction were identified, involving many processes: secondary metabolism, lipid metabolism, hormones. Transcriptome analysis of the Orobanche genome was underway. Genetic analysis of sunflower resistance to broomrape was discussed in the papers by Louarn et al. (France) with seven QTLs detected, and Celik et al. (Turkey) who presented detection of three QTLs in an F2 population including one parent resistant to race $\mathrm{F}$. These three QTL were positioned on LG7, 11, 12, with an R2 of 21.5 to $35.1 \%$. However, the methodology related to phenotyping was not mentioned. Among the presentations addressing varietal evaluation, Terzic et al. (Serbia) received particular attention: since 1996, wild species of Helianthus had been assessed to identify new sources of resistance potentially transferable to sunflower. A total of seven annual species and 182 accessions were evaluated in the field and/or greenhouse: H. annuus was found to be the most susceptible, unlike H. petiolaris, H. debilis and H. argophyllus, which showed behavior of interest to diversify sunflower resistance. Pfenning et al. (BASF), reported chemical control field trials carried out between 2012 and 2015 in Bulgaria, Hungary, Romania and Spain which showed an improvement in the effectiveness of the Clearfield Plus solution (Pulsar Plus + genotype tolerance based on a gene, see below) compared to the Clearfield ${ }^{\infty}$ solution., Marie et al. (Moldova) presented a study showing that a rotation of sunflower of at least four years, with preceding crops of maize or wheat reduced infestation levels. Limagrain-Soltis launched in 2013, the SUNEO brand for hybrids combining genetic resistance to broomrape and Clearfield herbicide resistance (Rita et al.).

\subsection{Pests, not many communications}

Only three communications dealt with pests. Renzi et al. (Argentina) focused on sowing dates to escape from the mite Nysius simulans, which damages sunflower and also soybean in Argentina. Prasifka (USA) presented studies on the variability and resistance processes of sunflower to three insects: Homoeosoma electellum (American sunflower moth, Pyralidae), Smicronyx fulvus (Red sunflower seed weevil, Curculionidae) and Cochylis hospes (Banded sunflower moth, Tortricidae)) by exploring in particular the toxic substances present in trichomes. Anastasiades (Greece) made an inventory of harmful and beneficial insects observed on sunflower in the 
Northern Greece between 2010 and 2015, but without quantification. It may be noted that no communication dealt with birds, which are widely frequently sunflower pests, both at sowing and at pre-harvest stage. This point may reflect both the complexity of the subject and too limited research investments.

\section{Weeds: in the absence of new herbicide molecules, reports focused on the practice of using imidazolinone tolerant varieties}

The plenary conference of Goran Malidza (Serbia) outlined the challenges and opportunities of integrated weed management in sunflowers. The very large expansion of the glyphosate market significantly reduced research efforts on new herbicide molecules with no new herbicides with novel modes of action on the market in the last 30 years. There was no hope for new herbicides in the coming years although invasive species such as ambrosia could cause yield losses of $70 \%$. In 2011, the Clearfield hybrid market represented 2.85 million hectare of sunflower in Europe compared with 240000 ha in 2007. The considerable development of this solution can be explained by its advantages: broad spectrum, including against broomrape, easy and effective spraying techniques, low cost, lower consumption of active ingredient and an interesting solution in simplified tillage systems, generally demanding in herbicides. However, already in 2016, its use faced difficulties, due to extension of the area treated and to weed species concerned by resistance problems, and the increased weeding cost, which followed. Recommended practices for this solution (place in the rotation, mechanical methods and use of the chemical solution as a last resort) were underlined. The author raised the question of the responsibility of seed companies in underestimating the problem of emergence of resistances, in the abandonment of prevention coupled with too greater confidence in chemistry and the desire to develop a very simple and broad-spectrum solution without ensuring the level of users' knowledge of weeds present on their farms. It was proposed that the part of the chemical control of sunflower weeds should decrease in the future with a return to mechanical control and cropping practices, provided that investments are made on the operational development of integrated weed control. Other communications on chemical weed control focused on BASF's Clearfield ${ }^{16}$ and Clearfield Plus solutions (Weston et al., Bessai et al.): presented in Argentina in 2012, the Clearfield Plus system is based on the same principle as Clearfield $^{\mathbb{B}}$ - inhibition of the enzyme ALS or AHAS - but differs by the use of a mutation different from AhasI. The main advantage of Clearfield Plus appeared to be the possibility to use more active ingredient (to be more effective on some difficult weeds species) without effect on sunflower (the "flash" effect of Clearfield ${ }^{\text {}}$ ).

\subsection{Agronomy: a synthesis of crop production and management papers}

The "Production and crop management" session was very heterogeneous, including 29 papers (11\% of the total).
The plenary conference by Philippe Debaeke (France) described the possible impacts of climate change for sunflower: increased photosynthesis for a $\mathrm{C} 3$ plant, reduced cycle length, increased number of stress days at high temperatures, increased water stress and water requirements, and finally interactions with biotic stresses. The simulations suggested losses of 10 to $30 \%$ yield in traditional growing areas in Europe, although consequences could also be positive with extension of the crop to some more northern areas, wider use of sunflower which is, among spring crops, the best adapted to dry conditions and possible double cropping (cycle of 100 days between two cereals). Sunflower could also benefit from its status as a low-greenhouse gas crop (three times less than winter crops such as wheat or rapeseed). Oil content may be reduced but high temperatures would favor accumulation of C18: one oleic acid. The production and quality of pollen could also be affected: more abortion or unfertilized seeds, in addition to possible consequences on interactions with bees and pollinators in general, which were still poorly known. Drier conditions are generally unfavorable for downy mildew, sclerotinia, phomopsis or even phoma, but, on the contrary, warmer and drier conditions would increase Macrophomina and early ripening. Levers of adaptation evoked were the use of genotypes with of "conservative" profiles in non-irrigated situations (shorter cycle, drought tolerance and crop resilience after the stresses) and "productive" profiles in irrigated conditions and also changes in cropping systems, with earlier planting, systems of three crops in two years (subject to irrigation) and reduction in sowing density. Debaeke concluded on crop models that have been continuously improved but for which further work was needed with regard to climate change: especially concerning high temperatures and the thermal weather model, the effects of heat shocks on photosynthesis and seed development, the effects over time of water and $\mathrm{CO}_{2}$ stresses and, related to high temperatures, successions of stresses and plants' recovery capacities. Simulations predicted an increase in sunflower yield in the northern regions, and a decrease in yields in the southern regions. Increased $\mathrm{CO}_{2}$ concentration in the atmosphere would only partially offset negative impacts of high temperatures, water stress and reduced cycle time. As sunflower is a low GHG-emitting crop, it appeared of interest to insert it in future cropping systems.

Effects of climate change were already noticeable in some countries, such as Argentina where there had been a significant reduction in the number of frost days over the year: $-35 \%$ between the 1980s and 2016, with the consequence that there could be new cycles for some biting insects (especially coming from arboriculture) on young achenes (Nysius simulans) without effective solutions (Renzi et al., Argentina). In Turkey, Balkan et al. conducted a climate change assessment for the periods 2016-2040, 2041-2070 and 2071-2099, based on models of multiple correlations between yield and climate variables over the last 30 years for 10 provinces of the Marmara region. Simulations based on the IPCC RCP8.5 climate scenario (some of the worst) showed mixed results across provinces, with declines in yields in half of the situations, and reversals of trends over time, with large positive or negative effects in some regions. These first studies of possible impacts of climate change on sunflower cropping highlighted both risks and opportunities and the need for 
further reflections, taking into account different geographical scales, and also some questions of physiology and pest biology.

In varietal evaluation, genetic progress was evaluated in Argentina by Tassara and Bock with the comparison of the oil yield of 27 conventional, oleic, herbicide-tolerant, both oleic and tolerant herbicide hybrids, marketed between 1984 and 2015 by Syngenta in a test network covering four environments in 2014-2015: the gain was evaluated on average at $1.8 \%$ per year. The company Euralis presented an approach to develop its hybrids, combining climate analysis (definition of homogeneous zones from Spain to Russia) with the use of the SUNFLO crop model (Gautier et al., France). Four types would be required in Europe, based on 10 indicators in three phases of the cycle. Analysis of genotype $\times$ environment $\times$ management interactions on these four groups made it possible to reinforce decisions positioning hybrids on the market. Mohamed and Mohamed (Sudan) also discussed genotypeenvironment interactions using cultivars from various seed companies over 10 years.

Seed treatment by Trichoderma harzianum were reported by Yonsel and Sevím (Turkey), to lead to better root development and 10\% increase in chlorophyll tissue content and $15 \%$ increase in yield, based on field results in Turkey and Ukraine between 2006 and 2014. Young roots colonized by T. harzianum appeared to be covered with mycelium and this colonization may also protect against soil pathogenic fungi. The authors also suggested that T. harzanium produced organic acids that affect the availability of phosphates. Results did not detect any incompatibility with conventional seed treatments at the recommended doses.

\section{Production, outlets and markets}

Several presentations provided information on country situations and developments current in 2016. Yildiray Gençer, president of TURKTOB, the Turkish Seed Growers' Association, presented the Turkish seed sector: $\$ 1.5$ billion in sales, and $\$ 150$ million in exports, of which sunflower seed accounted for one-third. In Turkey, oil consumption per capita was $27 \mathrm{~kg} /$ year, oil self-sufficiency at about 59\%. Sunflower then accounted for $46 \%$ of annual oilseed production: its production increased by $98 \%$ in since 2000 to reach 1.8 million tons in 2015. Sunflower was the oil most consumed in Turkey, with $0.9 \mathrm{MT}$ out of 1.7 MT in total including $1 \mathrm{MT}$ of liquid oils and 0.7 MT of concrete oils (palm and palm kernel). Sunflower was also developing in Ukraine and Russia, with an increase of more than 1 million ha in 2016. Between 2005 and 2010, sunflower exploded in these regions $(+6$ million hectare) with large improvements in yields, which reached $2 \mathrm{t} /$ ha or more. Mohamed and Mohamed presented the state of the sunflower crop in southeastern Sudan. As in West Africa, two growing cycles are possible (rainy season or irrigation). The interest was for both food oil and protein markets, and agronomically to break the cotton/sesame/peanut rotation. Yields remained low (between 0.5 and $1 \mathrm{t} / \mathrm{ha}$ ) but oil contents were satisfactory $(42 \%)$. Selection of the best hybrids adapted to local conditions (short cycle, tolerance to climatic shocks and the main bioaggressors) was engaged with the involvement of private breeders (Syngenta, Advanta) and the country's university teams. The authors estimated at 50000 ha the potential for sunflower in Sudan. In India, sunflower acreage decreased from 2.3 million ha in 2006 to 600000 ha in 2015 . However, the potential of commercial varieties continued to increase (from $0.99 \mathrm{t} /$ ha in 1970 to $1.5 \mathrm{t} / \mathrm{ha}$ in 2010 ), but was not apparent on farms (with $0.75-1 \mathrm{t} / \mathrm{ha}$ ). Sunflower was also introduced on cotton-dominated areas with the aim of breaking monoculture. There was a sharp decline in the share of hybrids from private companies in favor of those from the public.

Pilorgé (France) presented perspectives from the results of a scenario-based foresight study on the future of oilseed and protein crops in 2030, concluding that the protein fraction of oilseed crops, both for human and animal consumption could become essential for the maintenance of the competitiveness of these crops and was a major challenge, but that the value of oil would remain dependent on nutritional aspects.

Oil quality symposium: Fabrice Turon (France/Oils \& Fats Associates) analyzed current and future positioning of sunflower on the high oleic oil market. He observed that sunflower was growing at an annual rate of $2.7 \%$, not driven by biofuels. There had been an increase in Russian and Ukrainian sunflower crops, which reached about $6 \mathrm{Mha}$ each, and a decline in the rest of the world, especially in South America. The export market had increased, especially with the growing demand from China, India, Egypt and Turkey. Turon concluded that growth was driven by food demand and quality oriented. He also observed that the value of sunflower still depended more on the oil fraction than on the seed meal. The market was divided between conventional and oleic sunflower, and the oleic expansion was not correlated with the changes the in conventional oil market, suggesting that the two types can be considered as different and independent products. Since 2014, there had also been a disconnection (not a bonus) between the prices of oleic and conventional oils, which may have resulted from the attention paid to the suppression of trans fats, limited by regulations, first in North America, then in the European Union from 2011, where the trans content must not exceed $2 \%$. The same regulations would follow in Asia. Turon suggested that after the suppression of trans, a second step would be the reduction of saturated fatty acids. In 2016, product labels already indicated total fat, saturated fatty acids and trans-fat contents. The objective for the industrialists was to display zero trans. Oleic sunflower production was estimated at $11 \%$ of world production. Nurkam Turgut Dunford (Oklaoma St Univ, USA) offered historical depth by recalling that until the 1960s, mainly animal fats were used for frying, until scientific studies blamed them for their effect on health. Until 2006, the US FDA considered trans fats to be healthy (GRAS status) and trans were used as additives. Sunflower oil has useful characteristics for food applications, including its light color, which does not interfere with food formulations, and permitted new applications such as encapsulation of volatile oils and flavor compounds, or oleogels. The author also pointed out the interest of sunflower olosomes, made of $68 \%$ lipids, $6 \%$ proteins and $26 \%$ humidity, which, in native form, make it possible to produce emulsions rendering addition of stabilizers unnecessary. She mentioned a series of new applications: sunflower oil-based gels that can be used to deliver medicinal or nutritional substances and edible films that can be used for the protection of food. Some applications, such as flavor encapsulation, still required research. The author concluded on the improvements that 
have still to be made on sunflower oil, especially oxidative stability, for which, surprisingly, it appeared lower than rapeseed oil. Phytosterols were the subject of three papers covering description and interest for human nutrition. Improved analyses characterizing phenolic compounds identified new molecules of interest from commercial refined sunflower oils (the most abundant phenolic compound was rutin at $2.7 \mathrm{mg} / \mathrm{kg}$, followed by chlorogenic acid at $1.6 \mathrm{mg} / \mathrm{kg}$ and vanillic acid at $1.35 \mathrm{mg} / \mathrm{kg}$ ). These concentrations were obviously not comparable with those found in other studies on whole seeds or meal. Velasco (Spain) focused on phytosterols, important compounds for human nutrition because of their proximity to cholesterol: the health effects of phytosterols boosted the functional food market, and breeding research on phytosterol levels started quite recently. It is known that the source/sink relationship affects oil composition, but without references to phytosterols. Velasco performed experiments on the source/sink ratio by defoliation or removal of seeds, and then analyzed the phytosterol levels: he did not observe a clear effect of source/sink ratio, the strongest effects being related to genotype. However, it appeared that increase in the source/sink ratio tended to increase seed phytosterol content but had no effect on oil. Work was also carried out on natural additives: the addition of bitter orange oil (anti-oxidant) makes it possible to reduce the fraction of free fatty acids and to improve the peroxide value, and this would be a good alternative to the addition of synthetic antioxidants such as BHT (Erdogdu and Bozdogan, Turkey). Çevik and Ünver (Turkey) presented the development of an indicator (linoleic acid/stearic acid ratio) to detect adulterated sunflower oils: of 36 samples from different parts of Turkey controlled, four had aberrant indexes (mainly following the addition of cottonseed oil). Dauguet (France) presented the philosophy, organization and results of the health quality monitoring plan for French oilseeds (PSO). An interprofessional approach, which oilseed companies join on a voluntary basis (commercialization and storage organizations, oil mill and feed industries) pools data concerning contaminant analyzes on oilseeds, oils and meal. Examples of results were cadmium content of seeds and meals and detections of pesticide residues. The interest of such a collective approach also made it possible to propose changes of regulatory thresholds, as was the case for the MRL (Maximum Residual Level) of pyrimiphos-methyl where the data of the PSO contributed to the recognition of the existence of crosscontaminations. The other interest is also to encourage stakeholders to improve their practices.

\section{Confectionary sunflower has specific R\&D needs}

Several papers focused on confectionary sunflower. Nada Hladni (Serbia) gave an update on the situation and perspectives. About $10 \%$ of the annual production of sunflower was used in 2011 for a use other than oil. Market demand and surfaces tended to increase due to its nutritional value and use in human nutrition. The confectionary sunflower was particularly present in Turkey, China (more than $60 \%$ of sunflower crops, 600000 ha), USA (90\%), Canada (50\%), Russia (500 000 ha), Ukraine, Israel, Argentina, Pakistan and Iran. In contrast, production of this type of sunflower was low in the European Community where imports were important. Different markets depended on consumer demands (e.g. different seed size or color depending on the country), which made breeding programs difficult and expensive. There was little breeding in the world recently, and to increase the interest of the confectionary sunflower, several criteria needed to be improved: yield, rate of self-fertility, resistance to diseases (including downy mildew and rust), broomrape, herbicide resistance, drought resistance. The criteria specific to confectionary sunflower were first and foremost protein content $(>25 \%)$ for its nutritional value, reduction in oil content $(<40 \%)$, and oil stability, followed by seed and kernel size $(\mathrm{PMG}>100 \mathrm{~g})$, shape and color, hull reduction $(<35 \%)$ and ease of peeling. There was still little knowledge of the genetic variability that exists within this pool. Studies by Zuil (Argentina) highlighted the advantage of oilseed breeding using hybridization between oilseed and confectionary lines to reduce the consumption of seeds by birds (especially those of the colombidae family): big seeds appeared to be less prone to bird damage. Results on the effects of inter-row spacing, nitrogen dose and organic fertilizer inputs on the yield and characteristics of sunflower seeds were presented by S. Day and Süzer (Turkey).

\section{Sunflower proteins: a resource requiring better use for a more competitive crop}

To improve the quality and protein content of sunflower seed meal, one solution lies in hulling, which eliminates a significant part of the cellulosic fraction. S. Dauguet presented French work on the interaction between this technique and genotype. Studies showed that hulling can increase the protein content of meal from $27-29 \%$ (dry matter) to potential levels of 34 to $44 \%$, this wide range of variation being explained both by the variability of seed protein contents from the different varieties (33 to $41 \%$ on de-oiled dry matter) and their hullability, measured by the amount of hull extracted by a standardized process of laboratory hulling (3.7 to $14.7 \%$ ). Prediction equations for protein content in meal have been developed based on the seed protein and fiber contents. Karwasra and Dhiya (India) reported studies on processes with commercial or laboratory sunflower meal for making chapatis from meal and protein isolates. Incorporation of $10 \%$ meal in wheat flour appeared an optimum, without degradation of product organoleptic quality. These supplemented products could help to reduce infant protein and energy malnutrition in India.

\subsection{Non-food uses}

Ion et al. (Romania) reported on the "biomass" outlet for biogas production, for which sunflower is interesting, with a production of up to 10-15 tonnes of aerial biomass per ha, good rusticity and high oil content (increased production of methane compared to other crops): work carried out under the Romanian program "Partnerships for Priority Domains" focused on favorable conditions for biomass production (preceding effect and tillage, row spacing) but reported production between 8 and $9 \mathrm{t} / \mathrm{ha}$ only. Possible uses of sunflower starch (cellulose extracted from the stems) for 
plastics and xylose production were also reported by Halici Demir and Akpinar.

\section{Conclusions}

Despite the delicate geopolitical conditions, the Edirne International Sunflower Conference presented a fairly comprehensive state of sunflower research. Breakthroughs had been made in sequencing the sunflower genome and the dynamic has continued since the Conference. The International Consortium for sunflower genomic resources should play a key role in international coordination of efforts, which could justify a similar coordination on high-throughput phenotyping projects. This would help to improve collaboration between genomics, environmental interactions research and breeding.

Given the diversity of pests, the challenges of climate change and the multiplicity of uses that the sunflower crop must meet, the development and conservation of genetic resources are crucial. These activities are carried out by a small circle of countries, and the role of the United States is decisive for wild resources. Collaboration between gene banks is important and some specialization could help to reduce costs.

Segmentation of the sunflower market, which appears to be increasing, presents the obvious risk of dispersion of research and innovation capacities, especially in the private sector, for a species that traditionally mobilizes considerable efforts on genetics and breeding to solve the problems of diseases. For improved overall efficiency in use of resources, this situation requires reinforcement of cooperation on pre-competitive upstream material and dialogue between research and industry.

Changes in downy mildew and Orobanche races both entail considerable effort, using similar methodologies, especially to ensure satisfactory identification of races, essential for the use of monogenic resistance. However, these efforts, which are certainly priorities, should not lead to a disregard for the interest of exploiting variability to develop horizontal resistance. Other pathogens appear to be increasing threats (Verticillium, powdery mildew, Alternaria) in different countries, which require studies to understand their biology and to identify genetic variability available in sunflower.

It may be noted that there are few studies on crop pests. However, while it is agreeable that insect problems remain limited, this is not the case for bird damage, at sowing and preharvest. These attacks occur frequently and may be severe in certain situations, going as far as to question the viability of the crop. There is a clear need for international and multidisciplinary coordination (ecology, genetics, agronomy) of research-development-innovation activities to solve this complex problem.

Weed control is in a fragile situation due to the lack of innovation in terms of new herbicidal active ingredients: the success of imidazolinone tolerant varieties can be fragile over time, with the appearance of resistant species.

Finally, in terms of agronomy and physiology, it would be relevant to federate part of the efforts around crops models integrating phenotypic parameters and aggregating knowledge in simulation softwares that are very useful, despite their current limitations, to understand the future impacts of the climate change, to elaborate adaptation strategies, and to improve varietal choice in today's situations.

The general vision provided by the 2016 Conference was that the sunflower crop benefits from dynamic research. It faces a future with many challenges but also many opportunities related to a diversified demand and its characteristics of agronomic plasticity. The 20th International Sunflower Conference will be the occasion for scientists to provide answers to some of these challenges and to reinforce international collaboration.

Acknowledgments. The authors thank their colleague André Merrien for his contributions.

\section{Further reading}

The proceedings of the 19th International Sunflower Conference are available on line on the ISA website www.isasunflower.org, section "publications".

Cite this article as: Pilorgé E, Dauguet S, Jestin C, Mestries E. 2020. The main dynamics of sunflower research presented at the 19th International Sunflower Conference in 2016. OCL 27: 21. 